\title{
Effects of annealing gas species on the electrical properties and reliability of Ge MOS capacitors with high-k $\mathrm{Y}_{2} \mathrm{O}_{3}$ gate dielectric
}

\author{
C.X. $\mathrm{Li}^{1}$, H.X. Xu${ }^{2}$, J.P. Xu' ${ }^{2}$, P.T. Lai ${ }^{1, *}$
}

\begin{abstract}
In this work, Ge MOS capacitors with $\mathrm{Y}_{2} \mathrm{O}_{3}$ gate dielectric were fabricated. The effects of annealing in $\mathbf{N}_{2}, \mathrm{NH}_{3} \mathrm{O}_{2}$ or $\mathrm{NO}$ ambient were investigated. Experimental results demonstrated that the NO annealing could improve both electrical properties and reliability of Ge MOS devices with $\mathrm{Y}_{2} \mathrm{O}_{3}$ dielectric. On the other hand, the $\mathrm{NH}_{3}$ annealing resulted in $\mathrm{H}$-related traps while the $\mathrm{O}_{2}$ annealing suffered from extra $\mathrm{GeO}_{x}$ growth, thus both degrading the performance of the devices.
\end{abstract}

\section{INTRODUCTION}

In order to improve the speed of MOS devices while scaling down the size of MOS devices, Ge MOS devices are researched due to high electron and hole mobilities of Ge. Also high-k materials such as $\mathrm{HfO}_{2}{ }^{1-2}$, $\mathrm{ZrO}_{2}{ }^{3}$ and $\mathrm{HfTiON}^{4}$ have been investigated as the gate dielectric for Ge devices. However, the interface quality of high-k/Ge structure is not as good as that of the $\mathrm{SiO}_{2} / \mathrm{Si}$ interface. One of the main reasons is that unstable $\mathrm{GeO}_{\mathrm{x}}$ is grown during high-k gate-dielectric deposition and post-deposition annealing. Recently rare-earth oxides such as $\mathrm{La}_{2} \mathrm{O}_{3}{ }^{5}$ and $\mathrm{CeO}_{2}{ }^{6}$ were studied as the gate oxide for $\mathrm{Ge}$ MOS devices. But $\mathrm{CeO}_{2}$ has a small bandgap of $3.3 \mathrm{eV}$, which can cause large gate leakage current ${ }^{6}$; $\mathrm{La}_{2} \mathrm{O}_{3}{ }^{7}$ absorbs moisture, which can cause reliability problems. $\mathrm{Y}_{2} \mathrm{O}_{3}$ is a promising candidate for gate dielectric due to its relatively high dielectric constant ( 14-18), high crystallization temperature $\left(\sim 2325^{\circ} \mathrm{C}\right)$ and wide bandgap $(\sim 5.5 \mathrm{eV}){ }^{8 \sim 10}$. So far, $\mathrm{Y}_{2} \mathrm{O}_{3}$ is an interesting candidate for Si MOS devices, but there is little work on Ge MOS devices ${ }^{9}$. In this paper, $\mathrm{Y}_{2} \mathrm{O}_{3}$ is researched as the gate dielectric for Ge MOS devices, and the effects of annealing in $\mathrm{N}_{2}, \mathrm{NH}_{3}, \mathrm{O}_{2}$ or $\mathrm{NO}$ on the electrical properties of Ge MOS devices are investigated.

\footnotetext{
${ }^{1}$ Department of Electrical and Electronic Engineering, the University of Hong Kong, Hong Kong.

E-mail: laip@eee.hku.hk

${ }^{2}$ Department of Electronic Science \& Technology, Huazhong

University of Science \& Technology, Wuhan, P. R. China.
} 978-1-4244-4298-0/09/\$25.00 C2009 IEEE

\section{EXPERIMENT}

Germanium MOS capacitors were fabricated on (100) n-type substrate with a resistivity of $0.040 \sim 0.047$ $\Omega \mathrm{cm}$. The wafers were cleaned in organic solvent followed by a rinse in $2 \% \mathrm{HF}$ and de-ionized water for several times ${ }^{11}$. After drying with $\mathrm{N}_{2}$ gas, the wafers were immediately transferred into a sputtering system (Denton discovery series). $\mathrm{Y}_{2} \mathrm{O}_{3}$ film was subsequently deposited by sputtering $\mathrm{Y}_{2} \mathrm{O}_{3}$ target (99.9\% purity) in an Ar ambient. $\mathrm{Y}_{2} \mathrm{O}_{3}$ target received a $\mathrm{RF}$ power of $40 \mathrm{~W}$, and operating pressure was $4.4 \mathrm{mT}$ Torr. Post-deposition anneal (PDA) was performed in $\mathrm{N}_{2}, \mathrm{NH}_{3} \mathrm{O}_{2}$ or $\mathrm{NO}$ ambient at $500{ }^{\circ} \mathrm{C}$ for $300 \mathrm{~s}$, producing the control, $\mathrm{NH} 3, \mathrm{O} 2$ and $\mathrm{NO}$ samples respectively. Subsequently, Al was evaporated and patterned as gate electrode with an area of $7.85 \times 10^{-5}$ $\mathrm{cm}^{-2}$. Finally, forming-gas anneal $\left(5 \% \mathrm{H}_{2}+95 \% \mathrm{~N}_{2}\right)$ was implemented at $280^{\circ} \mathrm{C}$ for $20 \mathrm{~min}$.

High-frequency $(1-\mathrm{MHz})$ capacitance-voltage $(\mathrm{C}-\mathrm{V})$ characteristics were measured at room temperature using HP4284A precision LCR meter. Gate-leakage current was measured by HP4156A precision semiconductor parameter analyzer. The cross section of the samples was measured by TEM. Surface morphology was measured by AFM. High-field stress (at $10 \mathrm{MV} / \mathrm{cm}$ ) with the capacitors biased in accumulation by HP $4156 \mathrm{~A}$ precision semiconductor parameter analyzer was used to examine device reliability in term of gate-leakage increase after the stress. All electrical measurements were carried out under a light-tight and electrically-shielded condition.

\section{RESULTS AND DISCUSSION}

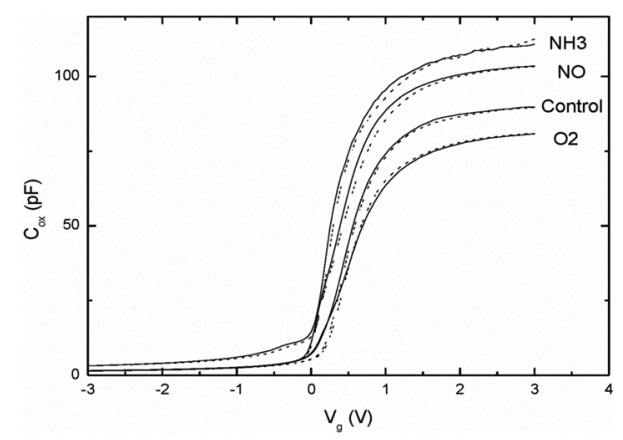


Fig.1 High-frequency (1-MHz) C-V curve of the Ge MOS capacitors.

Fig. 1 shows the C-V curves of the samples. Compared with the control sample, the capacitance of the $\mathrm{O} 2$ sample is smaller due to extra $\mathrm{GeO}_{\mathrm{x}}$ interlayer growth during the $\mathrm{O}_{2}$ annealing. However, the capacitances of the NO and NH3 samples are larger than that of the control sample, due to nitrogen incorporation. The incorporated nitrogen can increase the dielectric constant by passivating the oxygen vacancies which acts as vacuum or by replacing the oxygen atoms ${ }^{12}$. Among the samples, the NH3 sample has the largest capacitance, which is ascribed to the well-known best nitridation effect of the $\mathrm{NH}_{3}$ gas.

Table 1 lists the device parameters extracted from the high-frequency $\mathrm{C}-\mathrm{V}$ curves. Interface-state density at midgap is extracted by using the Terman's method for comparison purpose only. ${ }^{13}$ Compared with the control sample, the gate-oxide capacitance $\mathrm{C}_{\mathrm{ox}}$ of the $\mathrm{O}_{2}$ sample is decreased, due to extra growth of $\mathrm{GeO}_{\mathrm{x}}$ during the annealing. On the other hand, the $\mathrm{C}_{\mathrm{ox}}$ of the NO sample is increased due to increased dielectric constant, as mentioned above. The $\mathrm{V}_{\mathrm{fb}}$ is positive for four samples, indicating negative charges which may be related to trapped charges in the dielectric bulk or at the $\mathrm{Y}_{2} \mathrm{O}_{3} / \mathrm{Ge}$ interface. Comparing with the control sample, the NO and $\mathrm{NH} 3$ samples have negative $\mathrm{V}_{\mathrm{fb}}$ shift, implying positive charges formed during the PDA. This should be due to the nitrogen incorporation. In particular, the NH3 sample has more nitrogen incorporation, thus larger $\mathrm{V}_{\mathrm{fb}}$ shift. The midgap interface-state density $\left(D_{i t}\right)$ of the NO sample is lower than that of the control sample, due to the nitrogen incorporation which could passivate the dangling bonds in the bulk or at the interface, thus improving the interface quality. The $\mathrm{NH} 3$ sample has larger $D_{i t}$ than that of the NO sample, which could be explained by H-related traps created during the $\mathrm{NH}_{3}$ annealing. The $\mathrm{O} 2$ sample suffers from extra growth of $\mathrm{GeO}_{\mathrm{x}}$ which would generate defects at the $\mathrm{Y}_{2} \mathrm{O}_{3} / \mathrm{Ge}$ interface, thus larger $D_{i t}$ than that of the control sample.

Fig. 2 shows the TEM and AFM pictures of the control sample. It is shown that there is no obvious $\mathrm{GeO}_{\mathrm{x}}$ interfacial layer grown at the $\mathrm{Y}_{2} \mathrm{O}_{3} / \mathrm{Ge}$ interface, which should be attributed to the stability of the $\mathrm{Y}_{2} \mathrm{O}_{3}$ gate dielectric in contact with the Ge substrate. The AFM picture for the gate dielectric of the control sample shows very good surface morphology, with a surface roughness of $\sim 0.26 \mathrm{~nm}$ RMS. In a word, $\mathrm{Y}_{2} \mathrm{O}_{3}$ has good interfacial quality with germanium, with smooth interface and good surface morphology for the control sample.

From Fig. 3, it is observed that the NO sample has the smallest gate leakage current, indicating best interface quality (supported by its smallest $D_{i t}$ of $1.7 \times 10^{11}$ $\mathrm{cm}^{-2} \mathrm{eV}^{-1}$ ), ascribed to the nitrogen incorporation which could passivate the dangling bonds of the gate dielectric or at the $\mathrm{Y}_{2} \mathrm{O}_{3} / \mathrm{Ge}$ interface. Compared with the control sample, the gate leakage currents of the $\mathrm{O} 2$ and $\mathrm{NH} 3$ samples are increased, which could be explained either by the extra $\mathrm{GeO}_{x}$ growth during the $\mathrm{O}_{2}$ annealing or the H-related traps introduced during the $\mathrm{NH}_{3}$ annealing.

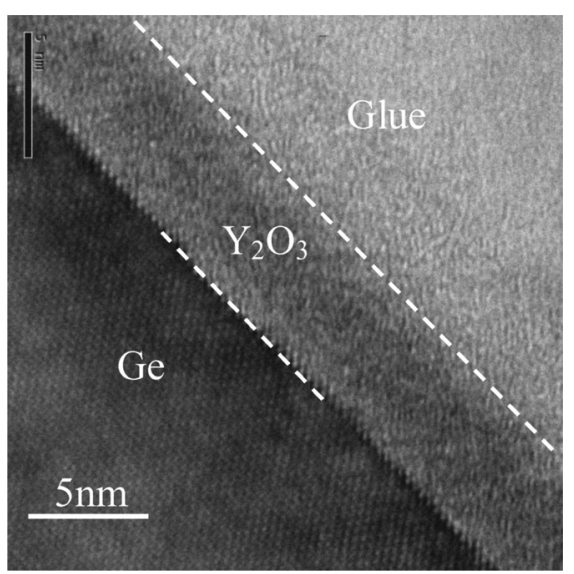

(a)

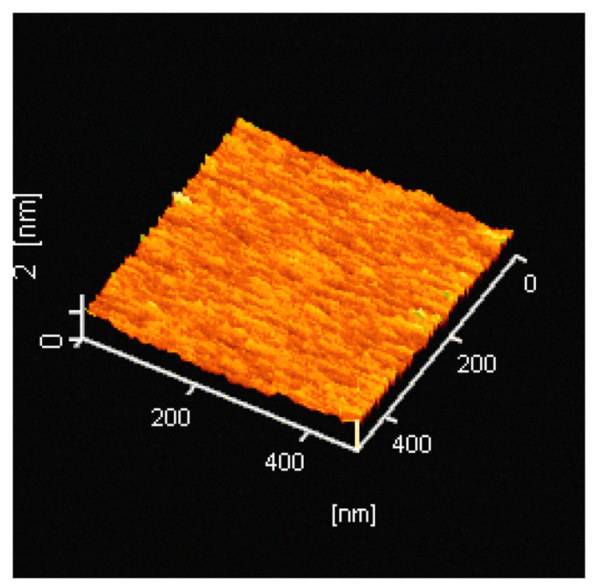

(b)

Fig. 2 (a) TEM and (b) AFM pictures of the control sample 
Table 1 Gate-oxide capacitance, equivalent oxide thickness, flatband voltage and midgap interface-state density extracted from the 1-MHz C-V curve, dielectric thickness measured by ellipsometer and dielectric constant for the samples.

\begin{tabular}{|c|c|c|c|c|c|c|c|}
\hline Sample & $\begin{array}{c}C_{o x} \\
(p F)\end{array}$ & $\begin{array}{c}t_{e q} \\
(A)\end{array}$ & $\begin{array}{c}V_{f b} \\
(V)\end{array}$ & $\begin{array}{c}D_{i t} \text { at midgap } \\
\left(\mathrm{cm}^{-2} \mathrm{eV}^{1}\right)\end{array}$ & $\begin{array}{c}Q_{o x} \\
\left(\mathrm{~cm}^{-2}\right)\end{array}$ & $\begin{array}{c}t_{\text {die }} \\
(\mathrm{nm})\end{array}$ & $k$ \\
\hline control & 89.8 & 30 & 0.33 & $3.9 \times 10^{11}$ & $-1.87 \times 10^{12}$ & 5.5 & 7.2 \\
\hline $\mathrm{NO}$ & 103.5 & 26 & 0.16 & $1.7 \times 10^{11}$ & $-1.55 \times 10^{12}$ & 6.1 & 9.3 \\
\hline $\mathrm{NH3}$ & 110.7 & 25 & 0.13 & $2.1 \times 10^{11}$ & $-1.45 \times 10^{12}$ & 6.0 & 9.5 \\
\hline $\mathrm{O} 2$ & 80.9 & 34 & 0.36 & $4.3 \times 10^{11}$ & $-1.85 \times 10^{12}$ & 6.2 & 7.1 \\
\hline
\end{tabular}

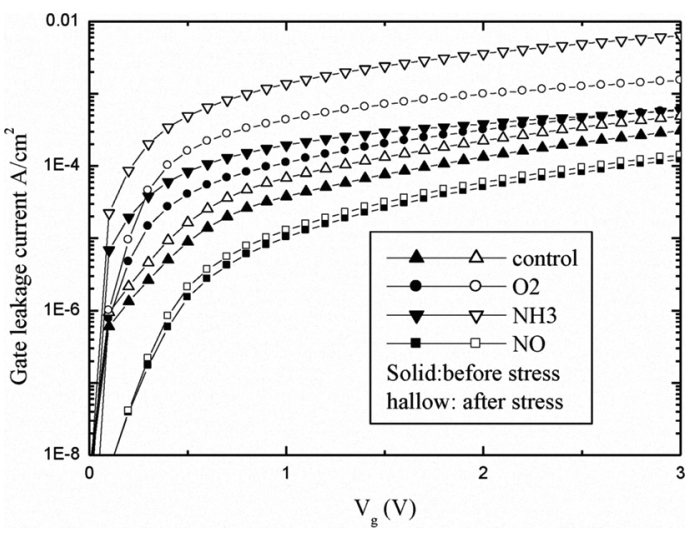

Fig. 4 Gate leakage current of the samples before and after stress

In order to evaluate the reliability of the samples, a high-field stress (at $10 \mathrm{MHz}$ for $3600 \mathrm{~s}$ ) is imposed on the samples. Fig. 4 shows the gate leakage currents before and after the stress. It is shown that the NO sample has the smallest increase of gate leakage current after the stress, while the NH3 sample has the largest increase of gate leakage current. The possible reason is that nitrogen incorporation can passivate the dangling bonds in the gate dielectric or at the interface, thus increasing the resistance against high-field stressing. On the other hand, the NH3 sample has a large number of weak $H$ bonds which could be easily broken during the high-field stress, resulting in large increase of gate leakage current. The $\mathrm{O} 2$ sample has extra growth of unstable $\mathrm{GeO}_{x}$, and thus large increase of gate leakage current after the stress and degraded reliability.
Rare-earth metal oxide $\mathrm{Y}_{2} \mathrm{O}_{3}$ is deposited as the gate dielectric of Ge MOS capacitors and then annealed in $\mathrm{N}_{2}$, $\mathrm{NH}_{3}$, NO and $\mathrm{O}_{2}$ ambient respectively. Experimental results show that $\mathrm{Y}_{2} \mathrm{O}_{3}$ has good interface quality with $\mathrm{Ge}$, with smooth interface and good surface morphology for the sample annealed in $\mathrm{N}_{2}$ gas. Also, the NO sample has the smallest midgap interface-state density and gate leakage current before and after stress, due to nitrogen incorporation. The NH3 sample suffers from hydrogen-related electron traps, leading to the largest gate leakage current and largest stress-induced leakage increase. In conclusion, the $\mathrm{Y}_{2} \mathrm{O}_{3}$ should be a promising candidate as the gate dielectric of Ge MOS devices, and the NO annealing could introduce sufficient nitrogen into the dielectric to improve the interface properties and enhance the reliability of the Ge MOS devices.

\section{ACKNOWLEDGEMENT}

This work is financially supported by the Research Grants Council (RGC) of Hong Kong Special Administrative Region (HKSAR), China, under Project HKU 713308E, and the University Development Fund (Nanotechnology Research Institute, 00600009) of The University of Hong Kong.

\section{REFERENCES}

[1] W. P. Bai, N. Lu, J. Liu, A. Ramirez, D. L. Kwong, D. Wristers, A. Ritenour, L. Lee, and D. Antoniadis, "Ge MOS characteristics with $\mathrm{CVD} \mathrm{HfO}_{2}$ gate dielectrics and TaN gate electrode," in VLSI Symp. Tech. Dig., 2003, pp. 121-122.

[2] J. J. Chen, N. A. Bojarczuk, H. Shang, M. Copel, J. B. Hannon, et al., "Ultrathin $\mathrm{Al}_{2} \mathrm{O}_{3}$ and $\mathrm{HfO}_{2}$ gate dielectrics on surface-nitrided Ge," IEEE Trans. 
Electron Devices, vol. 51, no. 11, pp. 1441-1447, Nov. 2004.

[3] S. K. Mandal, S. Charkraborty, C. K. Maiti, "Ge-channel p-MOSFETs with $\mathrm{ZrO}_{2}$ gate dielectric," Microelectronic Engineering, vol.81, pp.206-211, 2005.

[4] C. X. Li, P. T. Lai, and J. P. Xu, "Improved reliability of Ge MOS capacitor with HfTiON high-k dielelctric by using Ge surface pretreatment in wet NO," Microelectronic Engineering, vol. 84, no. 9-10, pp. 2340-2343, 2007.

[5] G. Mavrou, S. Galata, P. Tsipas, et. al., "Electrical properties of $\mathrm{La}_{2} \mathrm{O}_{3}$ and $\mathrm{HfO}_{2} / \mathrm{La}_{2} \mathrm{O}_{3}$ gate dielectrics for germanium metal-oxide semiconductor devices," J. Appl. Phys. 103 (2008) 014506

[6] D. P. Norton, J. D. Budai and M. F. Chisholm, "Hydrrogen-assisted pulsed-laser deposition of (001) $\mathrm{CeO}_{2}$ on (001) Ge", Appl. Phys. Lett. 76 (2003) 1677-1679

[7] Y. Zhao, K. Kita, K. Kyuno and A. Toriumi, "Band gap enhancement and electrical properties of La2O3 films doped with $\mathrm{Y}_{2} \mathrm{O}_{3}$ as high-k gate insulators", Appl. Phys. Lett. 94 (2009) 042901

[8] K.H. Kwon, K.L. Chang, J.K. Yang, et.al., "Effective formation of interface controlled $\mathrm{Y}_{2} \mathrm{O}_{3}$ thin film on $\mathrm{Si}(100)$ in

metal-(ferroelectric)-insulator-semiconductor structure", Micro. Engi. 85 (2008) 1781-1785

[9] L. K. Chu, W.C. Lee, M. L. Huang, et.al., "Metal-oxide-semiconductor devices with molecular beam epitaxy-grown $\mathrm{Y}_{2} \mathrm{O}_{3}$ on $\mathrm{Ge}$," Journal of Crystal Growth, vol. 311, pp. 2195-2198, 2009.

[10]C. O. Chui, H. Kim; D. Chi, P.C. McIntyre, and K.C. Saraswat, "Nanoscale germanium MOS Dielectrics-part II: high-k gate dielectrics," IEEE Trans. Electron Device, vol. 53, no. 7, pp.1509-1516, 2006.

[11]K. Tse and J. Robertson, "Defect passivation in $\mathrm{HfO}_{2}$ gate oxide by fluorine," Appl. Phys. Lett., vol. 89, pp. 142914,2006

[12]]L. M. Terman, "An investigation of surface states at a silicon/silicon oxide interface employing metal-oxide-silicon diodes," Solid-State Electron., vol. 5, pp. 285-299, 1962

[13] Paskaleva, A. J. Bauer, M. Lemberger, et.al., "Different current conduction mechanisms through thin high-k HfxTiySizO films due to the varying $\mathrm{Hf}$ to Ti ratio," J. Appl. Phys. 95 (2004) 5583-5590 